\title{
VIAGENS, MEMÓRIA, COLEÇÕES E ARQUIVOS NA NARRATIVA DE MURILO RUBIÃO
}

Hermenegildo José Bastos

Universidade de Brasília

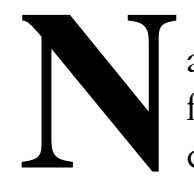

a ficção de Murilo Rubião, escritor mineiro, "agoniado nas fraldas da Mantiqueira", como o narrador de "Ofélia, meu cachimbo e o mar", a geografia é a das cidadezinhas do interior. Por isso o desejo do mar é marcante, e de tal forma que, ao menos inicialmente, se podem agrupar os personagens em "interioranos"/"litorâneos" ou ainda, "arcaicos"/"modernos". À serra opõe-se o mar, como ao confinamento a imaginação. O mar é o começo e mesmo a origem. A serra é o lugar do navio encalhado. A memória dos que vieram do mar se perde na escuridão das moles d'água, ouvem-se, porém, "as sirenes que cortam a noite como gemidos de homens que se perderam em águas distantes". ${ }^{1}$

Os personagens de Murilo são viajantes, fazem o comércio entre as cidades. De Acácio, de "Memórias do contabilista Pedro Inácio", o narrador diz que "Tinha um aguçado instinto de viajante que o levava a perseguir as mulheres onde quer que elas fossem". 2 O seu antepassado, Basílio da Câmara Bulhões e Couto, piedoso bispo, quando viajava de volta das Índias para Portugal, foi assaltado por piratas chineses e levado para a China.

O tipo mais comum de deslocamento nos contos de Murilo é a viagem de uma cidadezinha do interior (que está no passado) para a cidade grande (que está no presente). O espaço se funde com o

\footnotetext{
${ }^{1}$ RUBIÃO, 1998. p.114.

2 RUBIÃO, 1998. p.108.
} 
tempo. O meio de transporte é o trem. As tentativas de retorno para a cidadezinha em alguns casos não podem ser realizadas, porque o passado já não está disponível ("A noiva da casa azul"), em outros, contudo, parece se efetivar ("A fila"). Em alguns casos, o personagem muda de idade, de jovem torna-se subitamente velho ou, sendo velho, deixa ver o fantasma da juventude (como Hebe em "Os comensais"). Há também deslocamentos no interior da mesma cidade. Nesse caso, o transporte é o carro ("Epidólia" e "O convidado").

Em "Bárbara", o sonho da personagem, confinada no sertão, é possuir o oceano. Procurando realizar o anseio dela, o marido lhe presenteia com uma pequena garrafa contendo água do mar. Não satisfeita, Bárbara quer ter "um navio, que é a coisa mais bonita do mundo". ${ }^{3}$ A avidez de Bárbara é por coisas líricas. O caminho para a beleza é o do aniquilamento. A beleza, ou a arte, é o que há de mais lindo mas também de mais terrível. É o signo do horror.

O mundo-da-vida no qual o navio é a coisa mais bonita é marcado pela alienação. Os personagens são sombras, aí estão como prisioneiros. O mar também é uma prisão, porque a imaginação é doente. Assim, a oposição serra/mar, que corresponderia a confinamento/imaginação, esconde uma identidade profunda. A imaginação tem os seus confins, debate-se com os seus limites.

Os desejos de Bárbara não são de liberdade, alimentam a insaciabilidade doentia. Para realizar o seu desejo, o narrador faz transportar o navio do litoral para o sertão. O navio é desmontado e transportado em um trem com muitos vagões. Assinalam-se aí duas épocas da história da expansão européia: a primeira, dos navios, é a época do tráfico de escravos, das pilhagens, a segunda, dos trens, é a da interiorização. O império ibérico é o passado do império inglês. É a viagem do capitalismo, ou da modernidade. Quando o cerco se fecha, não há mais homens mas sombras, seres coisificados, mercadorias.

Bem observado, o par "interioranos"/"litorâneos" é um jogo de encenação. Os personagens são todos descendentes de

${ }^{3}$ RUBIÃO, 1998. p.37. 
marinheiros, e estão todos afastados irremediavelmente do mar. Contudo, o outro par - "arcaicos"/"modernos" - faz sentido, pois o processo de interiorização se deu em várias etapas e diferenciadamente.

O desmonte do navio assinala, não o fim da aventura colonial, mas a sua atualização. Um reajuste do capital, como diriam os economistas. Os personagens são ex-marinheiros. Hoje, são funcionários da estrada de ferro, e viajantes. O trem dá conta da expansão.

A obra de Murilo, que estreiou no final dos anos 40, é uma resposta às imposições de modernização social mas também literária. A cidade grande avança sobre a cidade pequena. Entre elas a diferença é apenas de grau, pertencem ao mesmo universo.

Levados para a serra, os personagens relembram-se do mar. No mar estava a glória, as viagens, as descobertas, as conquistas, o heroísmo, a força e o poder. Os ex-marinheiros trazem o mar tatuado no corpo, como um fetiche. Em "Epidólia", da barba do velho marinheiro Pavão pendem moedas.

Os contos são fragmentos de uma narrativa maior, que conta a aventura colonial. Os descendentes dos marinheiros se interiorizaram, habitam o sertão. São eles que narram. As narrativas são cortadas por trens. Às vezes, apenas o apito do trem, que lembra aos moradores da colônia agrícola que "Além de nós, havia no mundo mais alguém". ${ }^{4}$

Apenas como uma reunião de fragmentos essa narrativa poderia se efetivar, porque já não é possível a unidade. As situações se repetem, ainda que os personagens tenham outros nomes, o que também é uma forma de deslocamento. São sombras de si mesmos, os personagens, e deslocando-se de um para outro conto, vagueiam como fantasmas, mortos que retornam porque não podem ser sepultados.

Os contos estão, um para o outro, como suplemento, não como complemento, porque, como fragmentos que são, só fazem reforçar a ausência de unidade, duplicam uma ilusão. ${ }^{5}$ Em outras

\footnotetext{
${ }^{4}$ RUBIÃO, 1998. p.23.

${ }^{5}$ Sobre o texto como suplemento cf. DERRIDA, 1967. p.314.
} 
palavras: cada conto é um duplo do outro. Mas são todos duplos, aquilo de que seriam a duplicação já não está disponível. Assim, é na forma literária que o duplo fantástico primeiro se manifesta. Quanto aos personagens, existem apenas no texto. Nada têm, em muitos casos, além do nome.

Procurarei aqui acompanhar a aventura colonial (ou aventura da modernidade) nos contos de Murilo. Em outros trabalhos em vias de publicação, trabalhei "Ofélia" e "Memórias do contabilista Pedro Inácio", contos em que as viagens, os descobrimentos e as conquistas aparecem mais nitidamente. Aqui se trata, portanto, de uma pesquisa mais ampla em andamento.

Em "Teleco, o coelhinho" e em "Ofélia, meu cachimbo e o mar", o narrador coleciona selos. Nos dois casos, o narrador se dedica a colecionar como uma forma de consolo pela impossibilidade de viver e realizar seus desejos de voltar ao mar. As coleções têm algo de perverso.

Os selos viajam o mundo. Franqueiam a postagem das correspondências. São marcas de distinção. Sinais de estirpe. Senhas de acesso ou de proibição. Legitimam documentos. São os carimbos da burocracia, os sinetes e as chancelas dos reis e nobres, a legitimidade das moedas.

Selo vem do latim sigillu. Dá assim uma idéia de algo sigiloso e até mesmo escuso. Temos, então, por um lado, a viagem que os selos fazem ou de que são lembrança, por outro, o selo como sinal de poder, ou ainda, como sinal, não de qualquer viagem, mas de uma em especial, a viagem do capital, a da modernidade e colonização.

Nos dois contos, o ato de colecionar decorre da nostalgia do mar. No início de "Teleco, o coelhinho", o narrador está "frente ao mar, absorvido com ridículas lembranças". " Mas uma voz vem quebrar-lhe a concentração. É a voz de Teleco, o qual, em seguida, afirma que também gosta de ver o mar. Um pouco diferente do que

${ }^{6}$ RUBIÃO, 1998. p.143. 
se tem dito a respeito desse conto, não se trata aí das metamorfoses de Teleco, pois ele próprio é já resultado de uma transformação. Na verdade, é o mar, ou Proteu, que se transmuda. Teleco é, sim, a sua primeira aparição.

A história que então lemos - as "ridículas lembranças" do narrador - é uma história do mar. Enquanto contempla o mar, com "os olhos fixos na praia", ele ouve a voz de Teleco. O mar apenas contemplado é o mar impossível. A contemplação projeta a história que vamos ler.

Subitamente, o leitor entra no mundo "real", isto é, no mundo que lhe é familiar: menor abandonado, cigarro, polícia, violência são os seus componentes. Mas o narrador-personagem se comove com "o jeito polido de dizer as coisas" de Teleco, dá-lhe o cigarro e abre espaço para que ele também possa ver o oceano. Tornam-se amigos, e o coelhinho passa a lhe contar "acontecimentos extraordinários, aventuras tamanhas". Para ser narrador desses acontecimentos, Teleco precisaria ter mais idade do que aparenta ter. A idade do mar, ou mais precisamente, da aventura colonial.

Essas aventuras são ridículas, porque relembram um poder que já não há - aquele dos descobrimentos marítimos. A nostalgia do narrador pelo mar é a de um ex-marinheiro. Mas Teleco é pura projeção sua, no início lírica, depois monstruosa, mas sempre fantasmagórica.

Teleco vai morar em casa do narrador-personagem. No primeiro momento, é um ser lírico: transforma-se em outros animais para "agradar ao próximo", brinca com as crianças e os velhos. Pela manhã é cavalo para a gurizada galopar; à tardinha ajuda anciãos ou inválidos. Tem antipatia pelo agiota, e se transforma em leão para ameaçá-lo. Mas para proteger o agiota existe a polícia, e Teleco é obrigado a desaparecer. Nesse primeiro momento, ele é dócil. As suas metamorfoses não se reduzem ao mimetismo, pois algumas vezes se transforma em pássaros que não existem.

Este é o sinal mais forte do lirismo - a liberdade de imaginação, a faculdade de ir além dos limites do real. Contudo, não é uma 
liberdade de Teleco, simples projeção do narrador, mas desse. Aí poderia estar o antítodo contra as "ridículas lembranças".

O que é esse além do que o mundo empírico já nos dá? Em Murilo, é a fantasia. Lamentavelmente, porém, a fantasia é o horror. Assim, o ex-mágico chega a mutilar as mãos para livrar-se da fantasia. A fantasia é a escravidão. Não que a realidade seja melhor, mas simplesmente porque não há mais realidade disponível.

No segundo momento, o narrador-personagem, que era solteiro e solitário, um dia discute asperamente com sua cunhada, em casa dessa, sobre "negócios de família". O mundo do ter avança. Teleco já não é uma criança. Ele agora quer ser homem. Mas o máximo que ele consegue é se transformar em "um mofino canguru".

Teleco aspira a ser sujeito e conta para isso com a ajuda de Tereza. Seu nome agora é Barbosa. Procura emprego. O narradorpersonagem o acha asqueroso, mas, já cativado pelos encantos de Tereza, permite que ele continue em sua casa. A relação Tereza/ Barbosa é tão alienada quanto a relação Tereza/narrador. Todos são objetos. Os sonhos agora são de poder.

Tereza é uma feiticeira como várias outras em Murilo: Viegas, Galimene, Astérope. Representam o poder de sedução do mundo da mercadoria. Tereza diz ao "mofino canguru": és um homem. Viegas diz a Cariba em "A cidade": você é o procurado, ou ainda, você e aquele a quem se procura são o mesmo. São mecanismos do reconhecimento, dispositivos da ideologia, que interpela o indivíduo em sujeito.

No terceiro momento da narrativa, Barbosa é expulso de casa e passa a trabalhar como mágico. A capacidade de se transformar, que anteriormente era uma forma de pureza, comercializa-se. A alusão à arte feita mercadoria, que está também em "O ex-mágico" e "Os dragões", é parte da história do mar. Barbosa ouviu o canto das sereias, ou da ideologia.

O narrador, já esquecido de Tereza, revive o seu interesse pelos selos. A sua coleção conta com exemplares raros: de difícil classificação? A raridade é sinal de distinção ainda maior, como um 
índice de realeza. Acentua o poder. Os álbuns da coleção são o lugar da má-consciência do narrador, o que nos faz supor que ele sabe mais do que nos conta. Quais os negócios de família e quais as rídiculas lembranças? Por que as lembranças são ridículas?

Uma noite um cachorro lhe aparece e se transforma imediatamente em pavão. Perdera o controle das transformações. É agora um simples objeto manipulado. O narrador se apieda e procura ajudálo. Mas ele se esvai nas transformações, a última delas "uma criança encardida, sem dentes". Está morto.

As lembranças, como vemos, são de fato ridículas. Os projetos do narrador estavam podres desde o início. Teleco é natimorto. É apenas mais um selo na coleção.

No segundo conto que vou abordar, "A fila", o narrador não é personagem, diferentemente do que ocorre em "Teleco, o coelhinho". Mas é a mesma má-consciência. Afinal, a terceira pessoa, especialmente na literatura fantástica, é só uma estratégia de criar um narrador-testemunha, que legitima os acontecimentos narrados. O protagonista não tem como narrar aquilo pelo que passa, mas sim aquilo pelo que já passou.

Também "A fila" narra "um assunto sigiloso", aquele que faz Pererico sair do interior, de trem, para a cidade grande. Ele precisa falar com o gerente da Companhia. Assim como ele, porém, centenas de pessoas aguardam pela sua vez. Pererico nunca é atendido. Entre ele e a gerência há o porteiro Damião, "um negro elegante" nas palavras iniciais do narrador. Damião é o poder ou o seu representante, o capataz, o carcereiro. Trava-se uma luta, uma queda de braço, entre Pererico e Damião. Sedução, suborno, agressão.

$\mathrm{Na}$ fila, Pererico recebe uma senha de número sempre muito elevado, o que justifica ou legitima o seu fracasso. De fato, ele está ali para não ser atendido. A senha é a marca da inacessibilidade, o selo, o carimbo ou moeda do não. Damião se vale também de um argumento: Pererico faz sigilo dos assuntos, por isso é punido. Oferece-lhe dinheiro em troca da revelação do segredo, que Pereriro recusa. 
De fato, essa é a luta que se desenvolve aí: a luta pelo desvendamento do segredo de Pererico. Damião passa a contar com a colaboração de Galimene, uma prostituta, que freqüenta o pátio da fábrica. Pererico só possui agora o dinheiro reservado para a passagem de volta, isto é, a sua senha secreta. Passa a aceitar a amizade e a comida de Galimene. Ela procura afastá-lo da fila. Convida-o para ir à cidade, "onde as mulheres são lindas".

Damião é asqueroso, assim como o "mofino canguru". Ambos inspiram asco, porque evidenciam a objetidade. Damião é objeto para Pererico, do mesmo modo que Barbosa é objeto para o narrador-personagem de "Teleco...". Na verdade, são os espelhos em que Pererico e o narrador de "Teleco..." temem se reconhecer. São os seus duplos.

Pererico ainda se recusa a "revelar a todo mundo um segredo que não me pertence". ${ }^{7}$ Mas é preciso que vá todos os dias à fábrica. Com o tempo, e após ter desferido um soco na boca de Damião, Pererico passa a recusar as senhas. Procura encontrar o gerente fora da fábrica. Mas jamais o encontra.

Algo separa Pererico de Galimene: ele vem da cidade pequena, do campo, enquanto ela é uma criatura do mar. Pererico tem saudade da lavoura e dos animais domésticos. Ela gostaria que ele esquecesse os bichos, o gerente, a Companhia e procurasse emprego. O mar é o caminho para seduzi-lo:

- Por que não aproveita o sol da manhã para ir à praia? Hoje ela fica cheia de belas mulheres.

- Não faz sentido dentro dos meus objetivos.

- Você conhece o mar?

- Nunca vi um!

- É pena. Prosseguia, contando uma porção de histórias marítimas, que conhecia bem, sendo filha de marinheiros, nascida nas docas.

As tentativas de Galimene são no sentido de levar Pererico a se submeter ao mundo da produção, ele deveria, assim, esquecer

7 RUBIÃO, 1998. p.204. 
a fila, os bichos e arranjar emprego. É preciso produzir. Mas ele agora se entrega às suas reminiscências. Quando se lembra, corre para a fábrica, mas o gerente morrera. Antes de morrer, atendera a todos, exceto Pererico, que lá não estava.

Com o insucesso, Pereriro resolve tomar o trem de volta. Galimene ainda tenta convencê-lo a ficar, nem que fosse para conhecer o mar. Mas ele viaja. No caminho, se alegra quando vê surgir na paisagem os primeiros rebanhos. E "À medida que contemplava bois e vacas pastando, retornavam-lhe antigas recordações, esmaeciam as do passado recente". ${ }^{8}$

É de se perguntar: o segredo, que não pertence a Pererico, pertence a quem? À cidade pequena, às camadas mais remotas da memória? Às comunidades interioranas, que se sentem ameaçadas pela modernidade? Mas a cidade grande também se sente ameaçada. Pererico é portador de uma senha que ele recusa mostrar. Uma senha que antecede a todas as outras que ele recebe na fábrica.

A viagem de Pererico lembra a de Cariba em "A cidade". Mas, diferentemente de Cariba, que não pôde retornar, Pererico tem a senha para a viagem de volta, isto é, economizou o dinheiro, preservou o selo, o passaporte, a identidade.

Quanto a Galimene, é preciso ainda sublinhar que ela conhecia bem "uma porção de histórias marítimas", que, entretanto, não chega a narrar. Mas o leitor pode relacionar essas histórias com as "rídiculas lembranças" do narrador de "Teleco...". Galimene sabe as histórias, como o narrador sedentário de Benjamin, não por tê-las vivido, mas por tê-las ouvido, já que é "filha de marinheiros, nascida nas docas".

A distância entre as cidades foi reduzida pelos navios, trens e carros. Duas cidades podem assim se juntar, formar uma só. Ao mesmo tempo, uma cidade pode se dividir em várias. Espaço e tempo se deslocam. Separam-se, recompõem-se. Em "A fila" as cidades sequer têm nome. São sinais vagos em um mapa de ilusão.

${ }^{8}$ RUBIÃO, 1998. p.210. 
$\mathrm{Na}$ verdade, de onde vem e para onde volta Pererico? Para ontem, dir-se-ia, se isso fosse possível.

Os caminhos de ida e de volta são devaneios, como chega a pensar Manfredo em "Epidólia". Manfredo não consegue se recordar que a cidade tem mar. Mas como lhe diz o gerente: "- Antes eram três localidades distintas: Natércia, Piropólis e a Capital. Tendo se expandido, encheram os vazios, juntando-se umas às outras. Com Piropólis veio o mar".?

Manfredo sai em busca de Epidólia, sua amada. Viaja no tempoespaço. De Epidólia só o desaparecimento é disponível. Essa a única evidência. Fantasma é aquilo que desaparece e volta a aparecer, é o monstro. O adjetivo substantivado 'fantasmagórico", diz BelleminNoël, é a arte de pôr em cena os fantasmas. O fantasma está, ao mesmo tempo, ausente e presente: "é alguma coisa, mas não é em si mesmo; o fantasma torna-se meio para a aparição daquilo que não é". ${ }^{10}$ Mas mesmo ausente, ele nos vê. Derrida diz do espectro que "Esta Coisa olha para nós, no entanto, e vê-nos não vê-la mesmo quando ela está ấ". ${ }^{11}$

Manfredo deveria procurar Pavão, pai-amante de Epidólia, num dos botequins da orla marítima. No trajeto, ele se convence da existência do mar, pois constata a ausência de vegetação, que ele notara na vinda. Encontra Pavão, velho marinheiro de cujas barbas pendem moedas - o homem-mercadoria. Pavão é, como o fetiche do dinheiro, ao mesmo tempo objeto de sedução e de repulsa. O corpo sedutor e asqueroso do dinheiro, que é sem corpo, mas equivale a todos os corpos, a tudo que é sensível e palpável.

Também o "mofino canguru" e Damião são sedutores e asquerosos. Sedução é o caminho que leva a completar o processo de interpelação do indivíduo como sujeito. Isso é que de fato seduz: chegar a merecer o reconhecimento como sujeito, poder responder

\footnotetext{
9 RUBIÃO, 1998. p.173.

${ }^{10}$ BELLEMIN-NOËL, 1972. p.3.

${ }^{11}$ DERRIDA, 1994. p.22.
} 
à pergunta "quem?" com um "eu" nítido e forte. Na sedução, porém, também há asco, porque enquanto não se atravessa todo o umbral do reconhecimento pela ideologia, enquanto a máscara não se assenta de todo, o que se vê é apenas o feto: o "mofino canguru".

Quanto a Pavão, ele é aquele que trabalhou no mar. Os que trabalham no mar são piratas, saqueadores, traficantes. O trabalho de compra e venda. Pavão é a figura do morto-vivo, saído da enciclopédia do fantástico, que arrasta correntes - as moedinhas presas na barba.

Convertido em valor de troca, o produto do trabalho humano entra numa relação fantasmagórica com outros produtos. Fantasmagórica porque, a partir de então, nada é mais o que é, sim o que vale para a troca. Marx assinala que uma vez estabelecida essa relação entre dois produtos, tudo o mais é apanhado no turbilhão que a tudo transforma em mercadoria, até mesmo o produtor, o homem. A mercadoria é um objeto fisicamente metafísico. Tem um caráter místico e misterioso. A isso chama Marx fetichismo. ${ }^{12}$

O corpo sublime do dinheiro não é o da moeda, do selo. As senhas são destrutíveis, o que não ocorre com o corpo do dinheiro. Esse persiste para além da deterioração do corpo físico dos selos.

Epidólia "não resiste ao sortilégio do mar e a ele retorna sempre". ${ }^{13}$ Em busca do fantasma, o leitor encontra apenas as suas roupas: uma peça íntima de Epidólia abandonada no hotel, o pijama de Manfredo, o terno que Manfredo toma emprestado para ir em busca de Epidólia, o vestido sujo da tia Sadade, o uniforme da marinha mercante de Pavão, o terno branco e as chinelas de lã do farmacêutico. Há também os inúmeros quadros que o pintor fez de Epidólia, uma outra coleção.

O roteiro do mar em Murilo Rubião é o do capital. O mar como uma fábrica de narrativas, as da colonização. Como já se sabe, desde

${ }^{12}$ MARX, 1986. p.46.

${ }^{13}$ RUBIÃO, 1998. p.177. 
Edward Said, não teria havido império sem romance. Murilo valeuse da escrita fantástica para descontruir a narrativa do império. A escrita fantasmagórica é a que encena os fantasmas, a que dá a ver o invisível, perceber o imperceptível, isto é, a espectralidade, a forma-mercadoria.

A relação entre as mercadorias, como diz Marx, oculta a relação entre os produtores. O fetichismo da mercadoria é o modo pelo qual as formas econômicas do capitalismo ocultam as relações sociais nelas subjacentes. ${ }^{14}$

Não existe realidade sem o espectro. O círculo da realidade, diz Slavoj Zizek, só pode ser fechado mediante um estranho suplemento espectral. A realidade não é a própria coisa, é sempre já simbolizada. Mas a simbolização nunca é total. Há sempre uma falha. Essa parte do real que permanece não simbolizada é que retorna sob a forma de aparições espectrais. O espectro dá corpo àquilo que escapa à realidade. ${ }^{15}$

Se o fantástico é o reaparecimento do recalcado, como se viu em Freud, ${ }^{16}$ em Murilo o fantástico é o reaparecimento de camadas mais remotas da memória, recalcadas por força dos processos destrutivos de modernização em país periférico. As coleções e arquivos com que deparamos são instrumentos de poder. Poder, em primeiro lugar, dos narradores, pois, como sempre, narrar é um exercício de poder. Mas além dos narradores, outros personagens são detentores de parte desse poder: Arquimedes, Pavão, Damião, Galimene etc.

"A fila" é um conto em que o poder do narrador se evidencia de modo especial. A voz que acompanha as desventuras de Pererico pretende ser imparcial, ausente. Contudo, é a voz de alguém que se distingue do protagonista, e distingue-se porque dispõe de outras condições, dentre as quais o acesso a arquivos vedados ao outro. No lugar para onde Pererico (o perecível) volta pasta o gado, as formas de produzir e comprar a vida são outras que não as do

\footnotetext{
${ }^{14}$ MARX, 1986. p.38.

15 ZIZEK, 1996. p.26.

${ }^{16}$ FREUD, 1954. p.170.
} 
narrador, nem de Damião, funcionário burocrático numa moderna organização.

Desde o início, o narrador de "A fila", mas também o narrador homodiegético de "Teleco...", sabe que o protagonista está fadado ao insucesso. A culpa é insuportável. Assim em "Bárbara", o narrador avalia de modo depreciativo o pedido da personagem: "Como poderia saber da beleza de um barco, se nunca tinha visto um e se conhecia o mar somente através de uma garrafa?!" Em seguida, ele embarca novamente para o litoral, fazendo uso de seu livre trânsito.

O confronto entre esses pontos de vista é também o confronto entre as formas de produção e sobrevivência, que se acentua nos momentos de modernização acelerada. À sua maneira, a escrita fantástica é também "modernização" ou "atualização" da forma literária. Murilo soube responder, de modo irônico, a essa exigência de "atualização", soube valer-se do fantástico para encenar os fantasmas da nossa modernidade tardia.

\section{Referências Bibliográficas}

Bellemin-Noël, Jean. Notes sur le fantastique. Littérature, 8, p.3-23, décembre 1972.

Derrida, Jacques. L'ecriture et la différence. Paris: Seuil, 1967.

Derrida, Jacques. Os espectros de Marx. O Estado da divida, o trabalbo do luto e a nova Internacional. Rio de Janeiro: Relume Dumará, 1994.

Freud, S. Das Unheimlich. Lo Siniestro. Obras completas, vol. XVIII, Psicoanálisis Aplicado. Buenos Aires: Santiago Rueda, 1954.

Marx, Karl. El capital. Critica de la economia política. México: Fondo de Cultura Económica, 1986.

Rubião, Murilo. Contos reunidos. São Paulo: Ática, 1998.

Zizek, Slavoj. O espectro da ideologia. In: (Org.). Um mapa da ideologia. Rio de Janeiro: Contraponto, 1996. 


\section{Resumo}

Na geografia da ficção muriliana opõe-se a serra ao mar. Os personagens são ex-marinheiros ou descendentes de marinheiros. A nostalgia do mar é pelo passado de ação e bravura. No presente da narrativa, habitam cidadezinhas do interior. Deslocam-se para a cidade grande ou esperam pelos seus representantes, que vêm civilizá-los. O navio foi substituído pelo trem, representando cada um uma etapa da história do capitalismo: a expansão ibérica e a inglesa. Narrase aí a aventura colonial. A escrita fantástica revela os espectros da aventura da modernidade, que vagueiam entre o passado e o presente. As camadas mais remotas da memória dessa aventura são as das cidades pequenas, as mais recentes, as da cidade grande. Confrontam-se modos diferentes de produção e sobrevivência. A má fé do personagem narrador denuncia a sua cumplicidade com os jogos do poder.

\section{Abstract}

In murileon's fiction geography, the mountain is opposed to the sea. The characteres are former sailors or sailors descendents. The nostalgia for the sea relates to the action and bravery of the past. In the narrative's present, they dwell in country little towns. They move to the big cities or they wait for its representatives to come and civilize them. The train was substituted for the ship, each one representing one step in capitalism history: the Iberian and British expansion. The narration of the colonial adventure takes place. The fantastic writing reveals the ghosts of the modernity adventure, who wander between past and present. The most remote layers of the memory of this adventure are the ones of the little towns, and the most recent, the ones of the big cities. Different ways of production are confronted with different ways of survival. The narrator's bad faith denounces his complicity in power games. 